\title{
RISKS OF MOULD GROWTH IN DIFFERENT BUILDING STRUCTURES
}

\author{
Ansis Ozoliṇšn ${ }^{1}$ Andris Jakovičs ${ }^{2}$ \\ ${ }^{3}$ Laboratory for mathematical Modelling of Technological and Environmental Processes, University of Latvia, \\ Zellu Str. 8, LV-1002 Riga, Latvia \\ E-mail:1ansiso@inbox.lv(correspondingauthor); ${ }^{2}$ andris.jakovics@lu.lv
}

\begin{abstract}
In the current paper the impact of real Latvian climate conditions on a variety of building constructions is inspected. The influence of the humidity on buildings' sustainability in three different building units has been appraised. Condensate risks in a multi-layer wall are analyzed by transient outdoor climatic conditions. Risks of mould growth are discussed in detail taking into account the properties of building materials, dependence of humidity on temperature and season. The effect of vapour barrier is analyzed from several aspects. Theoretical analysis has been done based on real test stands built in Riga. Some experimental results are obtained.
\end{abstract}

Keywords: moisture, multi-layer wall, mould growth, test stands.

\section{Introduction}

An analysis of sustainability of different building solutions is necessary. One of the factors that may have a negative influence on the sustainability of the buildings is moisture. U-value could significantly increase due to the water content in the building construction, therefore, building energy consumption could also increase. Condensate formation in the building construction can cause a serious damage. Mould growth which may result from high moisture also has a negative influence on the building sustainability and human health. Mould, decay and insect damage in buildings is caused when moisture exceeds the tolerance of structures, which may be a critical factor for durability and usage of different building materials.

Risks of mould growth have been intensively analyzed over the last years. The influence of relative humidity and temperature on mould growth, on several microfungi and mycelium in different types of building materials was investigated in (Isaksson, Thelandersson, Extrand-Tobin, Johansson 2010; Thelandersson, Isaksson 2013; Viitanen et al. 2011; Sedlbauer, Krus, Zillig, Kunzel 2001; Johansson, Bok, Ekstrand-Tobin 2013; Nielsen, Holm, Uttrup, Nielsen 2004; Johansson, P., Extrand-Tobin, Svensson, Bok 2012). Paper (Mundt-Petersen, Wallenten, Toratti, Heikkinen 2012) presents folos $2 \mathrm{D}$ visual mould chart taken int account $t$ the influence of duration on mould growth and decline of mould growththat illustrates how it is possible to use the known models of mould growth in the practical moisture safety design processes. Report (MundtPetersen, Harderup 2013) uses the mould chart ato analyze the risk of mould growth in the walls consisting of insulation material and wood. Literature overview about moisture safety in wood frame constructions is given in(Mundt-Petersen, Harderup 2013). In (Vahid, Kjellstrom, Kalagasidis 2012), mould growth risks were investigated in the ventilated attics in Sweden. Comparison of the measured and calculated relative humidity in building constructions was done in (Hagerstedt, Harderup 2011; Hagerstedt, Harderup 2011; Hagerstedt, Arfvidsson 2010; Hagerstedt, Harderup 2010).
Since the critical conditions for mould growth in different building materials have been widely researched in the laboratory conditions, it will be interesting to analyze moisture risks in the real building structures in the real climatic conditions. Although these investigations about moisture risks in building constructions have been done nowadays, experiments that compare different building structures with similar conditions (orientation, size, room volume, placement of windows and doors, loft, floor, roof, etc.) are rarely conducted. Moreover, this type of analysis for the Latvian climatic conditions has still not been performed. Therefore, the theoretical and experimental analyses of moisture risks in different building solutions of external walls are recommended in the conditions of the Latvian climate.

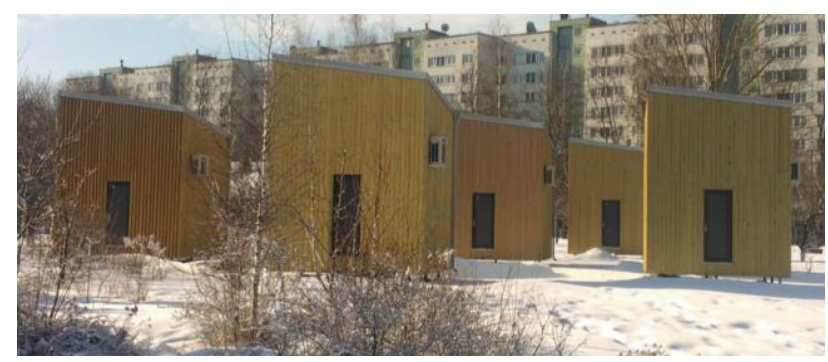

Fig. 1. Polygon of test stands.

To achieve the goal, five test stands of houses have been built for the first time in Riga, Latvia (see Fig. 1), and these stands can help to verify moisture risks and sustainability of the solutions developed for the constructions of external walls, which are mainly produced from the local raw materials (ceramic blocks, foam concrete, wood, plywood, fibrolite, granules, sawdust plates etc.), in the conditions of Latvian climate.

Overall, the main goals of the current work are to estimate the risk of condensate formation and mould growth for different building constructions with similar U-value in the real Latvian climatic conditions in the long term, using the real polygon of the test stands. More information about test stands and online results are available in (EEM, 2013). 


\section{Description of 3 test stands}

Experimental results of moisture risks in the building constructions have been obtained from the test stands of houses. All of them have the same orientation, net volume $\left(27 \mathrm{~m}^{3}\right)$, roof inclination, foundation depth over the ground. Construction floors and roofs are also of the same kind. Windows are added in the south wall for analysis of the influence of solar radiation on the heating and cooling energy and indoor thermal comfort conditions. The only significant difference between the test stands is building components used in the construction of the wall.

Three building constructions of multi-layer walls have been analyzed. The layers of the walls are listed in the direction from outdoors to indoors (see Table 1). The material data is obtained from software WUFI, which has been used in the simulations, material database and some data is provided by the manufacturers (Aeroc, 2013; Paroc, 2013). U-values with the thermal "boundary layers" of air are estimated approximately for wet conditions taking into account the change of thermal conductivity due to moisture. It is assumed that the convective heat transfer coefficient outdoors and indoors is constant $7.8 \mathrm{~W} /\left(\mathrm{m}^{2} \mathrm{~K}\right)$ due to the ventilated facade.

Table 1. Description of building construction walls

\begin{tabular}{|c|c|c|c|}
\hline Test stands & $\begin{array}{c}\text { Thickness } \\
\text { M }\end{array}$ & $\begin{array}{c}\text { Thermal } \\
\text { conductivit } \\
\mathbf{y} \\
\mathbf{W} /(\mathbf{m} \cdot \mathbf{K})\end{array}$ & $\begin{array}{c}\text { Water vapour } \\
\text { diffusion } \\
\text { resistance } \\
\text { factor } \\
{[-]}\end{array}$ \\
\hline $\begin{array}{l}\text { Stand of } \\
\text { plywood } \\
\text { Outside } \\
\text { Ventilated } \\
\text { facade } \\
\text { Plywood } \\
\text { Mineral wool } \\
\text { Plywood } \\
\text { Fibrolite } \\
\text { Lime plaster }\end{array}$ & $\begin{array}{c}0.02 \\
0.2 \\
0.02 \\
0.075 \\
0.015\end{array}$ & $\begin{array}{c}0.17 \\
0.036 \\
0.17 \\
0.068 \\
0.7\end{array}$ & $\begin{array}{c}700 \\
1 \\
700 \\
2 \\
7\end{array}$ \\
\hline U-value $0.13-0$. & $\mathrm{W} /\left(\mathrm{m}^{2} \mathrm{~K}\right)$ & & \\
\hline $\begin{array}{l}\text { Stand of } \\
\text { wooden logs } \\
\text { Ventilated } \\
\text { facade } \\
\text { Wooden logs } \\
\text { Mineral wool } \\
\text { Wooden log }\end{array}$ & $\begin{array}{c}0.2 \\
0.2 \\
0.04\end{array}$ & $\begin{array}{c}0.13 \\
0.036 \\
0.13\end{array}$ & $\begin{array}{c}130 \\
1 \\
130\end{array}$ \\
\hline U-value $0.13-0$. & $\mathrm{W} /\left(\mathrm{m}^{2} \mathrm{~K}\right)$ & & \\
\hline 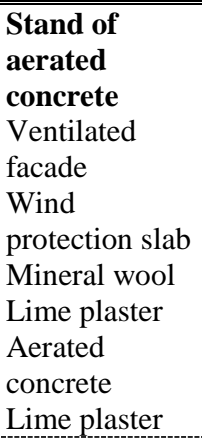 & $\begin{array}{c}0.03 \\
0.05 \\
0.015 \\
0.375 \\
0.015\end{array}$ & $\begin{array}{c}0.034 \\
0.036 \\
0.7 \\
0.072 \\
0.7\end{array}$ & $\begin{array}{l}1 \\
1 \\
7 \\
4 \\
7\end{array}$ \\
\hline
\end{tabular}

In the test polygon, a vapour barrier with $\mu=10000$ was placed behind the mineral wool on the side closer to the interior of the test stand made of wooden logs. No vapour barrier was used for the test stand from plywood. To analyze the effect of vapour barrier usage, the case with the vapour barrier added on the stand from plywood behind the mineral wool was also inspected.

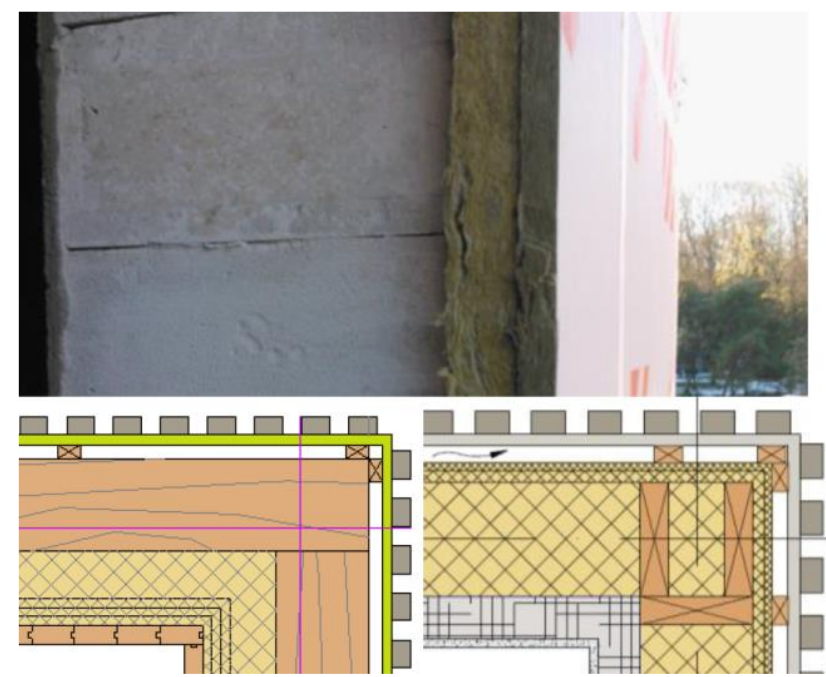

Fig. 2. Cross sections of multi-layered walls. Above: test stand from aerated concrete. Below: on the left - test stand from wooden logs; on the right- test stand from plywood.

Experimental houses are equipped with a full system for monitoring, collection and storage of data. Test stands are currently equipped with approximately 40 sensors for measuring electricity consumption, humidity and temperature in the rooms, lofts, facades, under ground, etc. Relative humidity sensors are also added in the walls of test stands. In the experimental case, we will inspect sensors located in constructions mainly consisting from the wooden materials and mineral wool. The first sensor is located in the interlayer between plywood and mineral wool outside in the wall of the test stand from plywood. The second sensor is placed in the interlayer between wooden $\log s$ and mineral wool outside in the wall of the test stand from wooden logs. Both sensors are located in the east of each external wall.

In the experimental case, indoor relative humidity was not controlled and was changed by free floating conditions. However, indoor temperature was controlled till May 8 to ensure temperature $18 \mathrm{C}$. After this day, the regime of the indoor temperature was changed by free floating conditions without heating and cooling. It was ensured that air change was similar for each test stand: $0.5 \mathrm{l} / \mathrm{h}$. 


\section{Weather data}
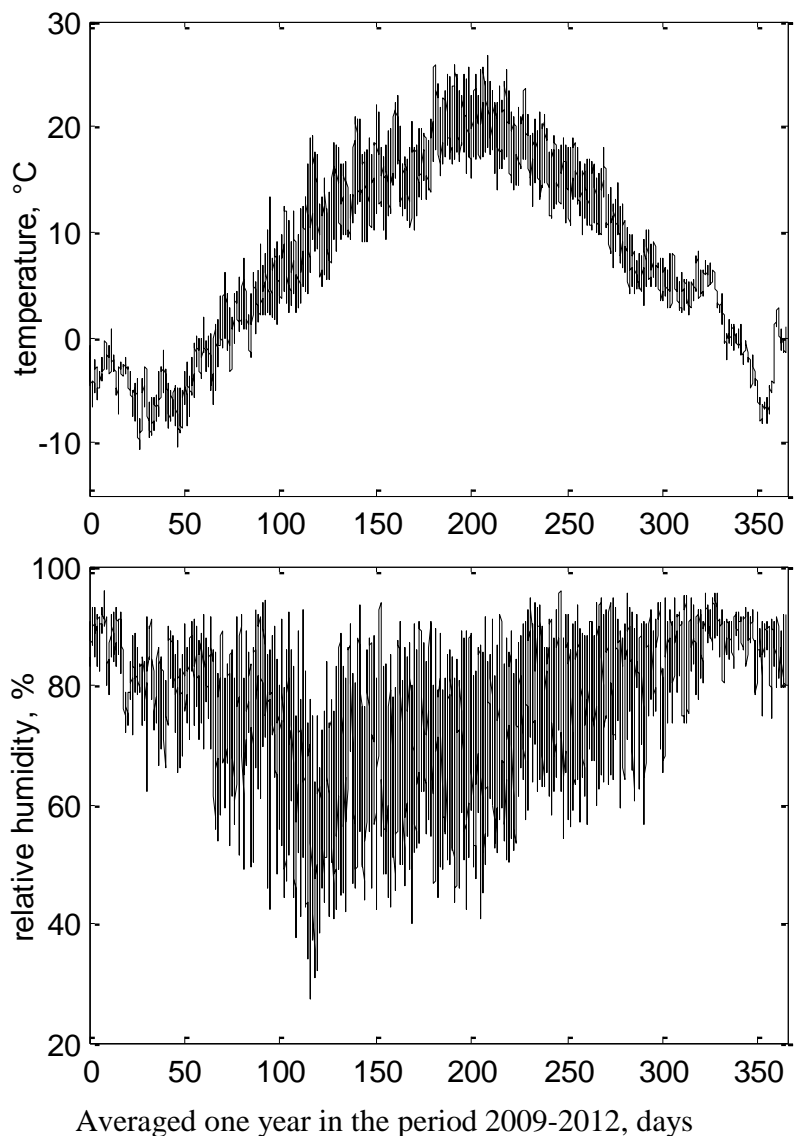

Fig. 3. Annual cycle of temperature and relative humidity, according to the Latvian climatic conditions in the long term.

The annual cycle was considered to analyze the risks of condensate formation and mould growth in the multilayered walls during a longer period (see Fig. 3). The meteorological data were taken from [19] by the time step of one hour for the relative humidity and temperature. The four year period from 2009-2012 was chosen and temperature was taken on the hourly basis, and these data were averaged. The reason for choosing that particular time period was to avoid weather anomalies that could appear in one year for a short time. At the same time, the weather data were not averaged too much, therefore variations of weather conditions during the time period of a few days was also taken into account.

The data for wind speed and direction, as well as the solar influence which is also shown in (Latvian Environment, Geology and Meteorology Centre database, 2013) was not used for simulations because the ventilated facade created for the test stands protected their walls (see Fig. 1). It was assumed that the temperature and relative humidity of the ventilated air layer are the same as those of the external atmosphere. For this reason the solar radiation through the wall boundary was not taken into account. The heat exchange coefficient must be the same as that of the interior air.
In the initial time period, when test stands were just completed, weather data, shown in Fig. 4, was used. This data was obtained from the meteorological station created in the polygon of test stands.
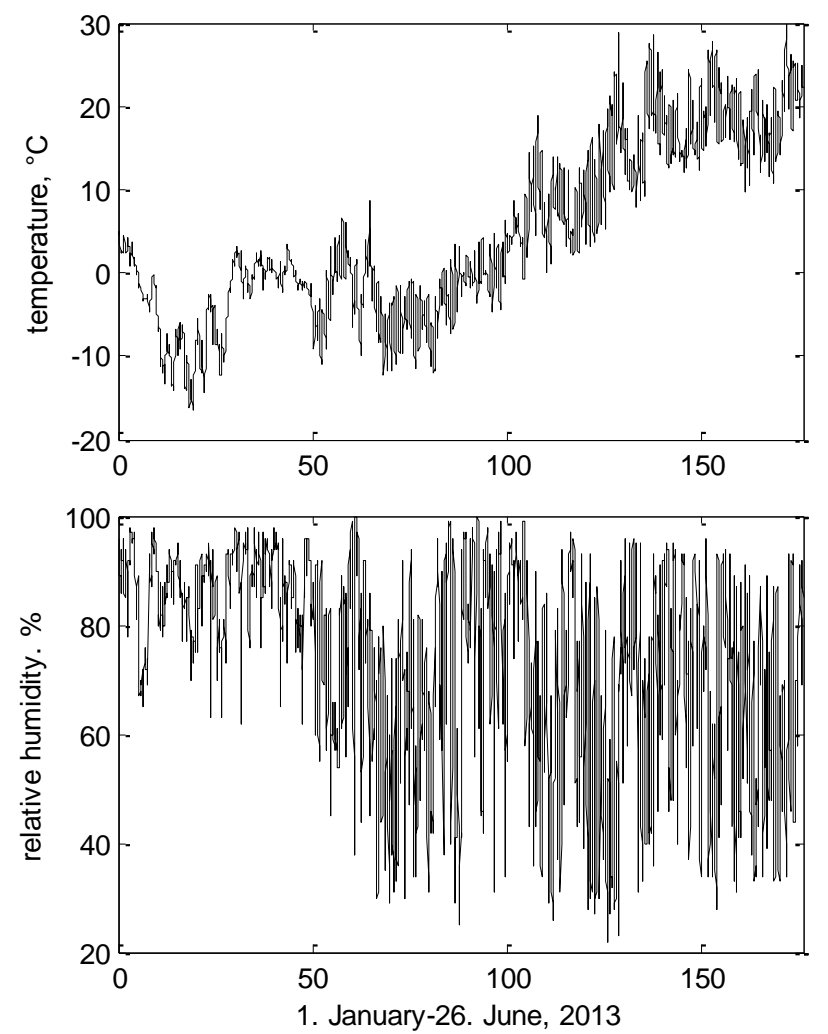

Fig. 4. Weather in the polygon of test stands. Initial period when the test stands were just completed.

\section{Simulation methods}

The commercial software WUFI®plus was used for the calculation of the simultaneous heat and moisture transport in multi-layered building components taking into account the whole building. The book (Kunzel et al 1995) describes in details the model used by software WUFI.

WUFI ${ }^{\circledR}$ plus is a room climate model which connects the energetic building simulation and the hygrothermal component calculation. Using the building simulation software WUFI ${ }^{\circledR}$ plus, the hygric and thermal ratios in a building, in its perimeter, and their interaction can be calculated and quantified as well as the energy demand and consumption of the system engineering. In the calculations of heat transfer in the multi-layered wall, WUFI takes into account thermal conduction, enthalpy flows through moisture movement with phase change and short wave solar radiation. Convective heat transfer by air flows has been disregarded, since it is usually difficult to quantify. The vapour transfer mechanisms included in WUFI are vapor diffusion and liquid phase diffusion. Convective vapor transfer by air flows has been ignored. 
The liquid transfer mechanisms taken into account are capillary conduction and surface diffusion. Seepage flow through gravitation, hydraulic flow through pressure differentials, as well as electrokinetic and osmotic effects have not been included. WUFI takes into account the hourly outdoor climate values.

\section{Results and discussions}

In this section, two cases are analyzed: long term climatic conditions and the initial time period, when test stands were just completed. Experimental results are given in the second case.

\subsection{Moisture risks in the multi-layared walls during a longer time period}

The results were obtained under the assumption that the indoor temperature and relative humidity are $+20^{\circ} \mathrm{C}$ and $50 \%$, respectively. The outdoor temperature and relative humidity are changing by annual cycles (see Fig. 2).

\section{Test stand from plywood}
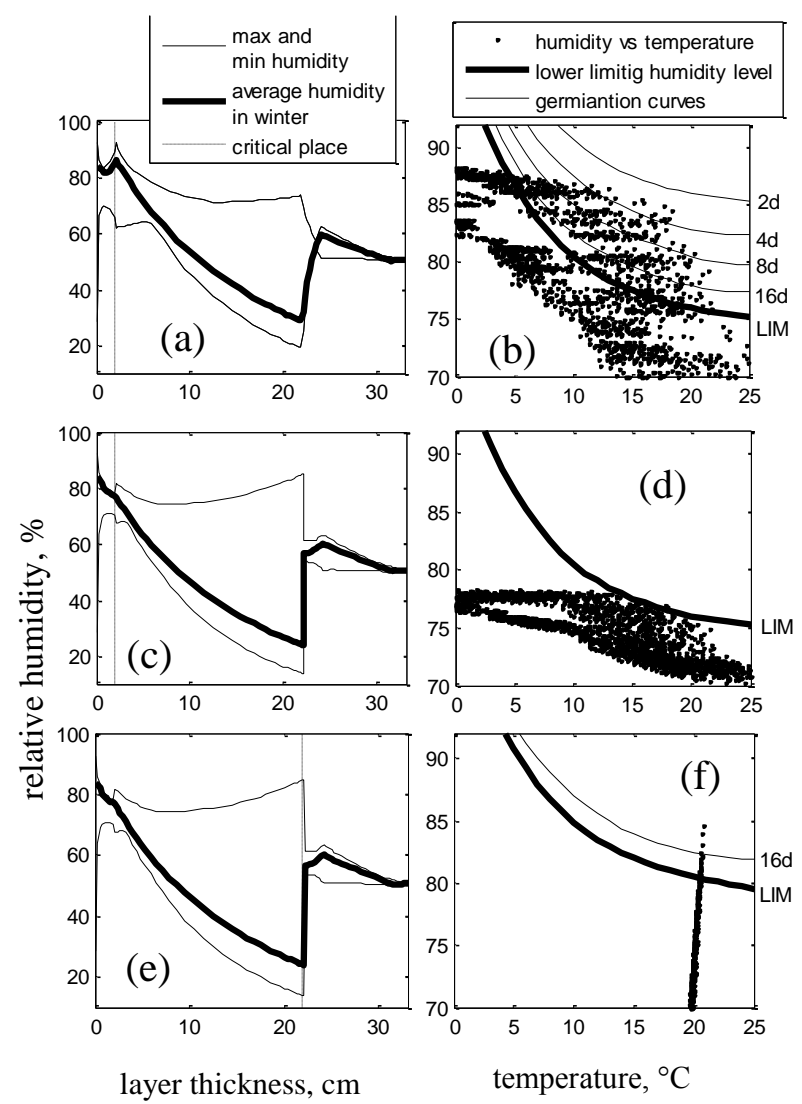

Fig. 5. Relative humidity curve (left) and relative humidity versus temperature in a specific place of the building wall (right). Vapour barrier is added on (c), (d), (e), (f) behind the mineral wool toward the interior of the stand. Dotted curve on (b), (d), (f) corresponds to the dashed line in (a), (c), (e), respectively.
For the calculation of the relative humidity in 3 test stands (see Table 1), the commercial software WUFI ${ }^{R}$ plus was used. The results presented below were obtained during one year, which is the $6^{\text {th }}$ year after five years from the initiation of calculations, when some building materials could have been wetter. The maximum and minimum relative humidity and the relative humidity in an average winter (for the purposes of the simulation it is assumed that the winter period lasts from December 1 to February 28) are calculated in the building construction.

The indications in days are the mould germination time, e.g., generalized isopleths system for spore germination. The number of days indicated marks the duration after which the first germination takes place. Lower limiting humidity level (LIM) shows the critical conditions for mould growth, see Fig. $5 \mathrm{~b}$, d, f, thicker solid line (Viitanen et al. 2011). Below LIM there is no biological activity. It is taken into account that LIM differs for biodegradable substrates (plywood, wooden $\operatorname{logs}$ ) and porous materials (mineral wool). Dots in Fig. 5b, d, f represent the humidity versus temperature relation in the annual cycle by a three hour time step.

Figure 5a shows that the test stand from plywood without the vapour barrier has a high risk of condensate formation. Vapour barrier effectively neutralizes this risk in the interlayer adjacent to the external layer, however, the risks of condensate formation and mould growth increase in the interlayer between the mineral wool and the plywood inside (see Fig. 5e, dashed line), that is explained by the fact that vapour comes in the direction from the outside to the inside in summer. Fig. 5e shows that the usage of vapour barrier can give an ambiguous effect. However, this risk is not so high in the reviewed case, e. g., total time when humidity can reach or exceed the limiting curve is only 70 hours. At the same time, it is expected that the relative humidity inside would be higher than $50 \%$ in summer, if cooling systems are not used, therefore the maximum relative humidity could be higher in a real situation. The risk of mould growth could also increase in summer if a stronger vapour barrier is used. 
Test stand from wooden logs

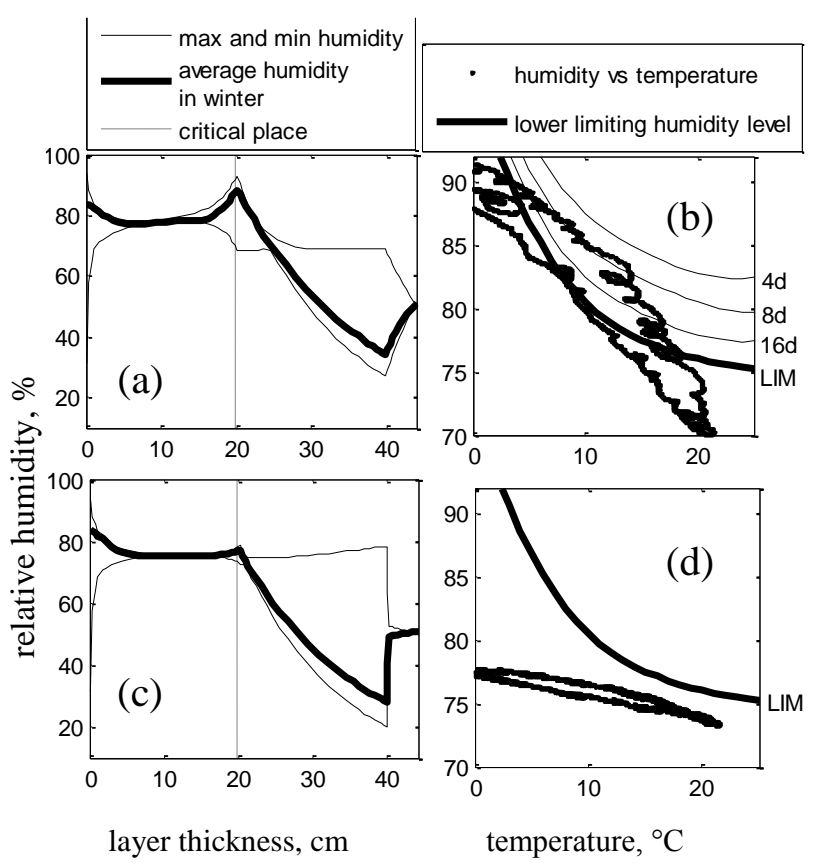

Fig. 6. Relative humidity curve (left) and relative humidity versus temperature in a specific place of the building wall (right). Vapour barrier is added on (c), (d), behind the mineral wool toward the interior of the stand. Dotted curve on (b), (d) corresponds to the dashed line in (a), (c), respectively.

Fig. 6 shows that the vapour barrier effectively neutralizes the risks of condensate (Fig. 6a against Fig. 6c) and mould growth (Fig. 6b against Fig. 6d) in the test stand from wooden logs. Maximal relative humidity is increased in the interlayer between the mineral wool and wooden log inside, however the risk of mould growth is not significantly in this case. Fig. $6 \mathrm{c}$ also shows that the level of relative humidity is changing insignificantly in the most part of wooden log outside due to a high water vapour diffuse resistance factor characteristic of wooden logs (see Table 1), therefore vapour diffuses slowly through the building construction.

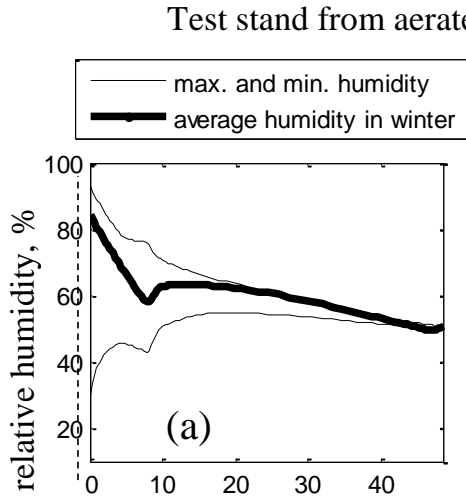

layer thickness, $\mathrm{cm}$

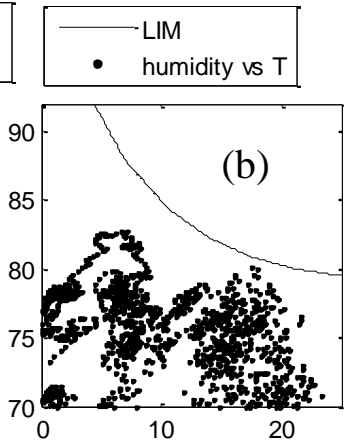

temperature, ${ }^{\circ} \mathrm{C}$
Fig. 7. Relative humidity curve (left) and relative humidity versus temperature in a specific place of the building wall (right). Dotted curve on (b) corresponds to the dashed line in (a) where wind protection slab is placed adjacently to the mineral wool layer.
In case of the test stand from aerated concrete, the highest relative humidity is observed on the wind protection slab outside (see Fig. 7a). However, the lowest temperature prevails in this place. The risks of mould growth are insignificant for the test stand from aerated concrete (see Fig. 7b). This can be explained with high vapour permeability of insulation materials and aerated concrete that allows vapour to diffuse relatively quickly through insulation materials, therefore the relative humidity is higher only in the winter period, when the temperature is low and risks of mould growth are lower due to a low outdoor temperature.

\subsection{Some experimental results on moisture in building constructions}

Tests stands of houses were completed in December, 2012. Some sensors were installed in the walls of each test stand, and results started to appear in April. Test stands mainly consisting of wooden materials and mineral wool are investigated in this section due to the highest moisture risks. Numerical results are obtained by software WUFI taking building geometry, weather data, boundary conditions on the wall, air change coefficients etc, as close as possible to real tests stands. Dots in Fig. 8, 9, 10, 11 represent the humidity versus temperature relation in the annual cycle by a one hour time step.

Test stand from wooden logs

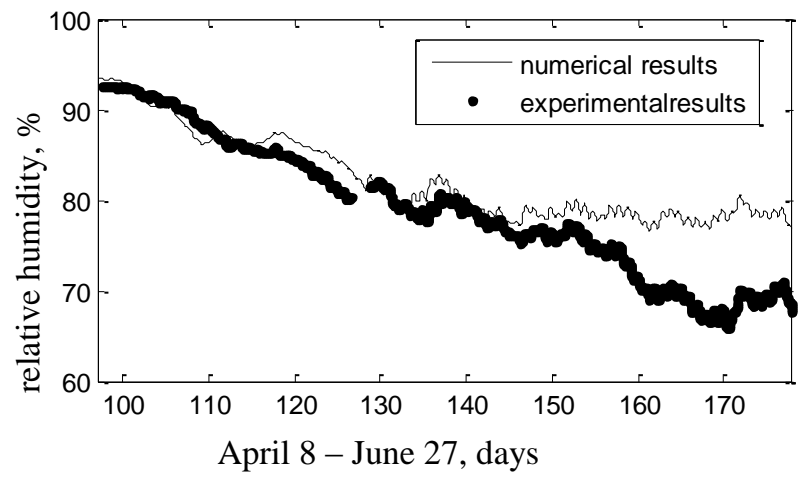

Fig. 8. The dynamics of relative humidity in a specific place of the building wall (see Fig. 5a, vertical dashed line) .

The difference between numerical results and experimental results (see Fig. 8) can be explained with inaccurately estimated diffusion resistance factor $\mu$ for wooden logs (see Table 1), which can be lesser in the real situation. $\mu$ value can also be lesser for the vapour barrier incorporated in the test stand from wooden logs. Therefore, vapours can diffuse quicker through the insulation materials and minimal value of relative humidity is lower in the test stand from wooden logs. Fig. 8 also demonstrates that the relative humidity changed from $93 \%$ to $66 \%$ during the period of 80 days, and this result significantly differs from the numerical result (see Fig. 6), where the amplitude was only 5\%. This can indicate that drying happens in wooden logs due to the higher moisture in the initial time period. As it was expected from theoretical simulations (see Fig. 6d), relative humidity is lower in summer. 
Test stand from wooden logs: April 8 - June

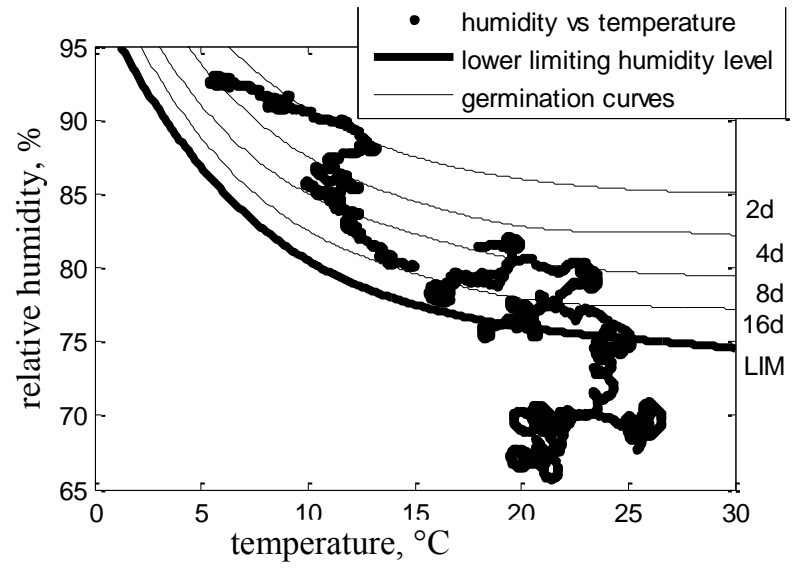

Fig. 9. Experimental results. Relative humidity versus temperature in a specific place of the building wall (see Fig. 5a, vertical dashed line)

Fig. 9 demonstrates that the risks of mould growth are high in the initial time period although numerical simulations showed (see Fig. 6d) that risks of mould growth is low in the long term.

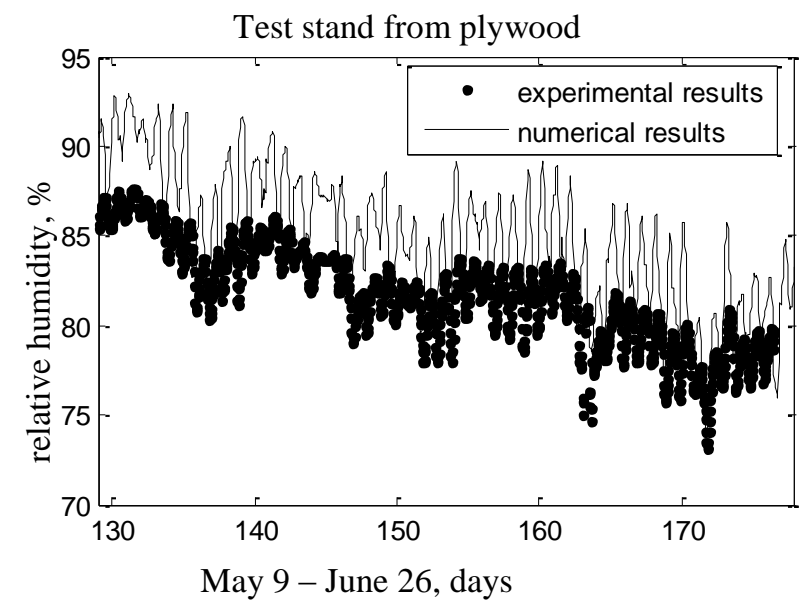

Fig. 10. The dynamics or relative humidity in a specific place of the building wall (see Fig. 6a, vertical dashed line).

Numerical results differ from the experimental results (see Fig. 10). It can be explained by the fact that relative humidity obtained from simulations is taken exactly from the interlayer adjacent to the external layer of the plywood house. However, the sensor can be placed not exactly in the interlayer, and that can slightly decrease the maximal value of relative humidity (see Fig. 5, dashed line). Nevertheless, numerical and experimental results are compatible enough for the test stand from plywood (see Fig. 10).
Test stand from plywood: May 9 - June 26

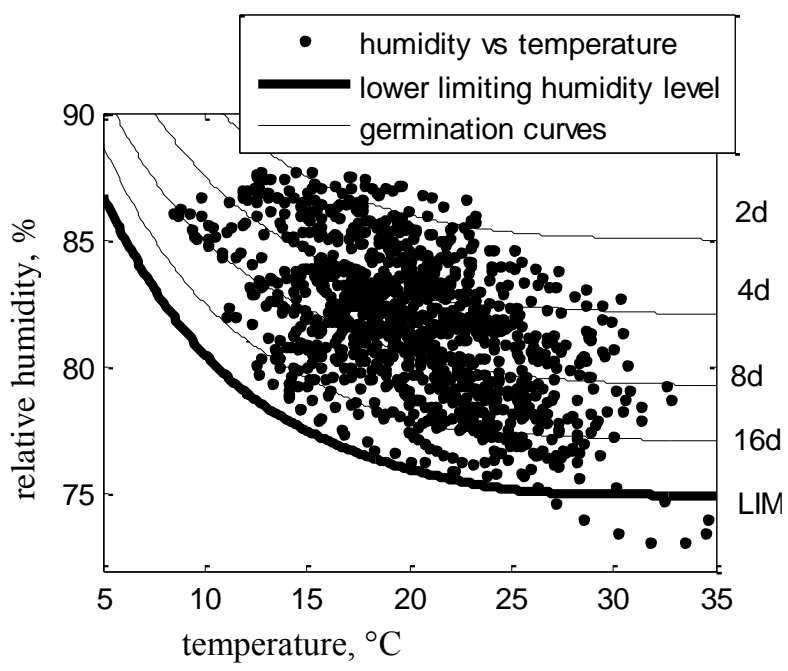

Fig. 11. Experimental results. Relative humidity versus temperature in a specific place of the building wall (see Fig. 6a, vertical dashed line).

Fig. 11 demonstrates that spore germination process occurred in the test stand from plywood. Relative humidity was above the lower limiting humidity level during almost the entire time period from May 9 to June 26 (see Fig. 11). That means that spore germination process definitely occurred in the test stand. That result coincides quite well with the theoretical simulation for a long time period (see Fig. 5). This result shows that moisture damages can appear if vapour barrier is not used in the test stand from plywood.

\section{Conclusions}

The current work demonstrates that moisture can have a negative influence on the building construction, e.g., the constructions which consist of wooden materials. The construction that consists of wooden logs is particularly prone to that risk due to relatively low water vapour permeability.

The vapour barrier can effectively decrease the risk of condensate formation and mould growth. However, the role of vapour barrier usage is ambiguous and potentially can heighten the risk of mould growth in the insulation material in the direction towards interior. In the observed cases, this risk was insignificant.

Experimental results demonstrate that critical conditions for mould growth are overreached for both tests stands consisting of wooden materials and mineral wool. Even the usage of the vapour barrier does not help the test stand consisting of wooden logs. 
The current experimental results concerned the initial time period, when tests stands were just completed. In future, the collecting of experimental data will continue, and that will allow analyzing the risks of mould growth in building constructions in the long term. The next experimental results will give a possibility to confirm or decline the hypothesis that the risks of mould growth are higher for constructions consisting of wooden logs and mineral wool in the initial time period.

\section{References}

Isaksson, T.; Thelandersson, S.; Extrand-Tobin, A.; Johansson, P., 2010. Critical conditions for onset of mould growth under varying climate conditions. Building and Environment, 45, pp. 1712-1721. Available at:

http://www.sciencedirect.com/science/article/pii/S0360132310 000351\# http://dx.doi.org/10.1016/j.buildenv.2010.01.023

Thelandersson, S.; Isaksson, T., 2013. Mould resistance design (MRD) model for evaluation of risk for microbial growth under varying climate conditions. Building and Environment, 65 , pp.18-25. Available at:

http://www.sciencedirect.com/science/article/pii/S036013231 3000966

http://dx.doi.org/10.1016/j.buildenv.2013.03.016

Viitanen, H., 2011. Moisture and Bio-Deterioration Risk of Building Materials and Structures, Mass Transfer - Advanced Aspects, Dr. Hironori Nakajima (Ed.),

ISBN: 978-953-307-636-2, InTech, Available at: http://cdn.intechopen.com/pdfs/23535/InTech-

Moisture_and_bio_deterioration_risk_of_building_materials _and_structures.pdf

Sedlbauer, K.; Krus, M.; Zillig, W.; Kunzel, H. M., 2001. Mold Growth Prediction by Computational Simulation. Fraunhofer Institute for Building Physics.

Johansson, P.; Bok, G.; Ekstrand-Tobin, A., 2013. The effect of cycle moisture and temperature on mould growth on wood compared to steady state conditions. Building and Environment, 65, pp.178-184. Available at: http://www.sciencedirect.com/science/article/pii/S036013231 3000267\#

http://dx.doi.org/10.1016/j.buildenv.2013.04.004

Nielsen, K. F.; Holm, G.; Uttrup, L.P.; Nielsen, P.A., 2004. Mould growth on building materials under low water activities. Influence of humidity and temperature on fungal growth and secondary metabolism. International Biodeterioration \& Biodegradation, 54, pp. 325-336. Available at:http://www.sciencedirect.com/science/article/pii/S0964830 504000782 http://dx.doi.org/10.1016/j.ibiod.2004.05.002

Johansson, P.; Extrand-Tobin, A.; Svensson, T.; Bok, G., 2012. Laboratory study to determine the critical moisture level for mould growth on building materials. International Biodeterioration \& Biodegradation, 73, pp. 23-32. Available at:http://www.sciencedirect.com/science/article/pii/S0964830 512001230

http://dx.doi.org/10.1016/j.ibiod.2012.05.014

Mundt-Petersen, S. O.; Wallenten, P.; Toratti, T.; Heikkinen, J., 2012. Moisture risk evaluation and determination of required measures to avoid mould damage using the Folos 2D visual mould chart. Thermopysics $2012-17^{\text {th }}$ International Meeting of Thermophysical Society, 31 October - 2 November, 2012, Podkylava, Slovakia.

Mundt-Petersen, S. O.; Harderup, et al., 2013. Blind evaluation of the hygrothermal calculation tool WUFI 5.0 using field measurements and determination of factors affecting the moisture safety. Building Physics LTH. Licentiate thesis. Available at:

http://www.byfy.lth.se/fileadmin/byfy/files/TVBH3000pdf/TVBH-3059SOMPlic_web.pdf

Mundt-Petersen, S. O.; Harderup, L. E., 2013. Moisture safety in wood frame constructions - What do we know today? - A Literature overview. Sustainable Building Conference 2013 SB13, 22-24 May, 2013, Oulu, Finland.

Vahid, M., N.; Kjellstrom, E.; Kalagasidis, A., S., 2012. Assessment of hygrothermal performance and mould growth risk in ventilated attics in respect to possible climate changes in Sweden. Building and Environment, 55, pp.96-109. Available at: http://www.sciencedirect.com/science/article/pii/S036013231 200039X\#

Hagerstedt, S. O.; Harderup, L. E., 2011. Comparison of measured and calculated temperature and relative humidity with varied and constant air flow in the facade air gap. $9^{\text {th }}$ Nordic Symposium on building Physics NSB. 29 May 2 June, 2011, Tampere, Finland.

Hagerstedt, S. O.; Harderup, L. E., 2011. Control of moisture safety design by comparison between calculations and measurements in passive house walls made of wood. XII DBMC - International Conference on Durability of Building Materials and Components, 12-15 April, 2011, Porto, Portugal.

Hagerstedt, S. O.; Arfvidsson, J., 2010. Comparison of field measurements and calculations of relative humidity and temperature in wood framed walls. Thermophysics $2010-$ $15^{\text {th }}$ International Meeting of Thermophysical Society, 2-5 November, 2010, Valtice, Czech Republic.

Hagerstedt, S. O.; Harderup, L. E., 2010. Importance of a proper applied airflow in the facade air gap when moisture and temperature are calculated in wood framed walls. $5^{\text {th }}$ International Symposium on Building and Ductwork Airtightness, 21-22 October, 2010, Copenhagen/Lynby, Denmark.

EEM, 2013. Test stand energy efficiency monitoring project. [Online] Available at: http://www.eem.lv

Aeroc., 2013. Available at: http://www.aeroc.lv/index.php?page=783\&lang=lat

Paroc., 2013. Available at: http://www.paroc.lv/

Latvian Environment, Geology and Meteorology Centre, database., 2013. Available at:

http://www.meteo.lv/meteorologija-datu-meklesana/?nid=461

Kunzel, H. M. et al., 1995. Simultaneus heat and moisture transport in building components. Fraunhofer Institute of Building Physics.

\section{Acknowledgements}

The current work was supported by the European Regional Development Fund in Latvia within the project No. 2011/0003/2DP/2.1.1.1.0/10/APIA/VIAA/041. 